\title{
Leiomyosarcoma of the anterior mediastinum
}

\author{
J . C.R. L I N C O L N \\ From the Brompton Hospital, London, S.W. $3^{1}$
}

Malignant tumours of smooth muscle are rare in the anterior mediastinum. The occurrence of leiomyosarcomata in the alimentary tract, uterus, broad ligament, urinary bladder, kidney, retroperitoneally, and wherever smooth muscle is normally abundant, is well documented. After a search of the world literature, no report of such a tumour sited in the anterior mediastinum could be found.

\section{CASE REPORT}

A. E., a 54-year-old housewife, presented with a sixweek history of lassitude and intermittent nocturnal pain in the left side of the chest. She gave no history of cough, excessive sputum, haemoptysis, or dyspnoea.

Physical examination revealed a well-nourished woman. There was dullness to percussion and diminished air entry over the left upper chest anteriorly.

Radiological examination of the thorax revealed a well defined mass with a lobulated outline extending from the centre into the left chest (Fig. 1 a). Lateral views showed that the mass was situated immediately behind and in contact with the sternum (Fig. 1 b). A chest radiograph at another hospital 18 months previously, following an accident. showed the tumour, which was then much smaller (Fig. 2 a, b).

Bronchoscopy demonstrated an inward bulge of the left tracheo-bronchial angle.

OPERATIVE DETAILS A left postero-lateral thoracotomy was done on 10 December 1962.

The left upper lobe was lightly adherent at the apex. The lung was normal. There was a lobulated, malignant-looking tumour in the superior and anterior mediastinum, arising in the left lateral lobe of the thymus, with its venous drainage into the left innominate vein. There was no obvious lymphadenopathy in the superior mediastinum.

The tumour was mobilized and excised together with the lateral lobe of the thymus. An extensive lymphatic clearance of the superior mediastinum was achieved.

POST-OPERATIVE PRogress The patient made an uneventful recovery from the operation and was

1 Present address : Surgical Init, University College Hospital Medical School, London W.C.1. followed up as an out-patient. She remained well for 14 months until February 1964, when she was found to have a firm spherical swelling $5 \mathrm{~mm}$. in diameter in the left temporal region. This remained unchanged in size until July 1964, when it increased in size, and in addition multiple metastases became evident involving the scalp, and, on radiological examination. the chest wall. An excision biopsy of the temporal swelling was performed, and histological examination revealed infiltration of temporalis muscle by a tumour histologically identical with the previous leiomyosarcoma (Fig. 5).

In August 1964 the patient began to complain of pain in the region of the metastases, and a course of systemic chemotherapy was started, busulphan (Myleran), $4 \mathrm{mg}$. daily, being given for three weeks; this did not alleviate the pain.

MACROSCOPY The specimen was an ovoid tumour $(15 \mathrm{~cm} . \times 10 \mathrm{~cm}$.) with a small nodulation on its surface.

The cut sections showed whorls of pale yellow tissue separated by strands of grey fibrosis. This appearance was constant at all levels. There were no areas of haemorrhage or cyst formation.

MICROSCOPY The tumour was composed of smooth muscle fibres, but there were areas in which many nuclei were large and bizarre (Fig. 3).

It was a leiomyosarcoma. The capsule was complete (Fig. 4), and the lymph nodes from the superior mediastinum and superior caval region were not metastasized.

Thymic tissue was present in one of the attached fatty tags.

Sections of the nodule in the left temporal region showed infiltration by a tumour histologically identical with the leiomyosarcoma (Fig. 5).

\section{DISCUSSION}

The tumour most frequently found in the anterior mediastinum is the teratoma (Blades, 1946; Lyons, Calvy, and Sammons, 1959). Vague intrathoracic discomfort, pleuritic pain, and dry cough are the most common symptoms caused by mediastinal tumours (Brewer and Dolley, 1949; Lyons et al., 1959). 


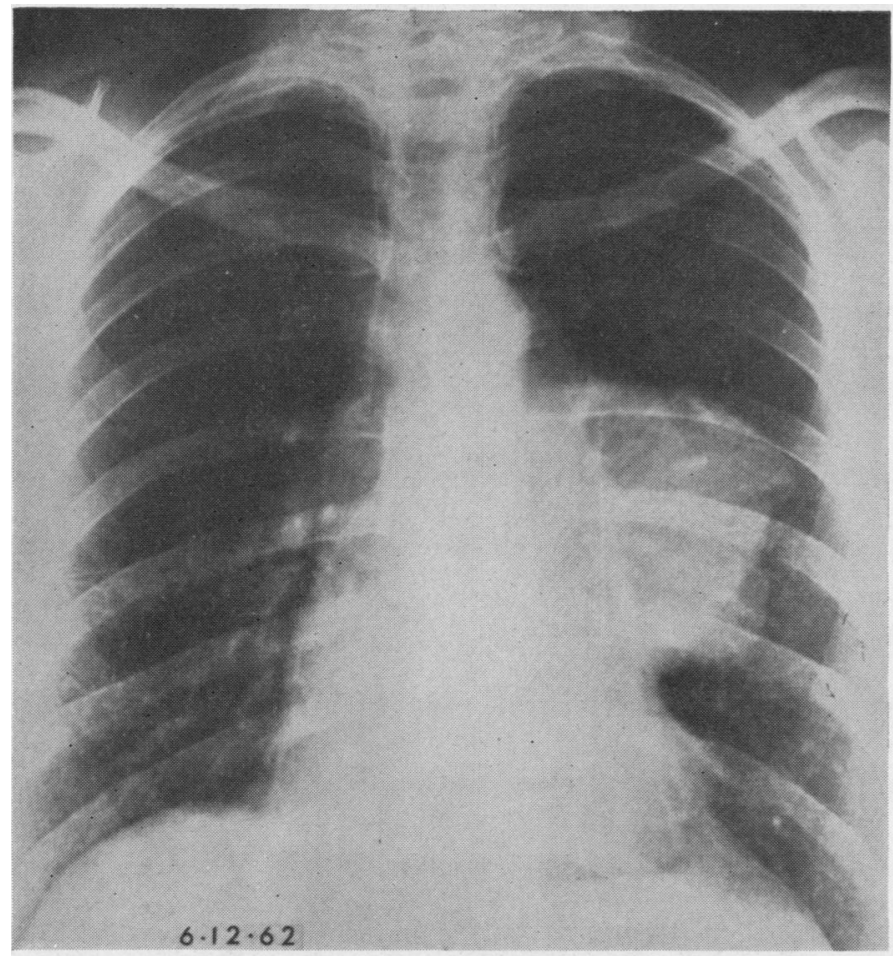

(a)

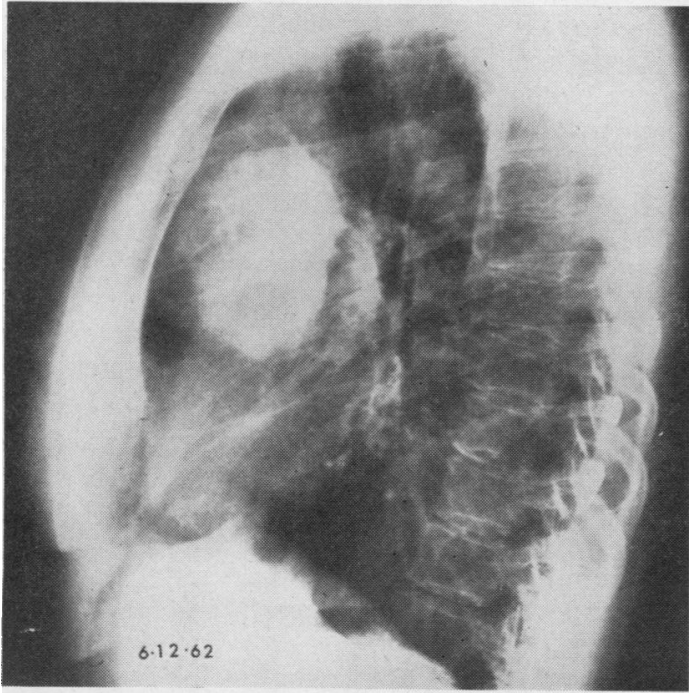

(b)

FIG. 1. (a) Postero-anterior and (b) left lateral radiographs showing a large mass with a lobulated outline projecting into the left chest and anteriorly into the anterior mediastinum.
Physical examination may be uninformative, widening of the anterior mediastinum may be noted on percussion; the diagnosis of an intrathoracic tumour may only be made after radiological examination consisting of postero-anterior and lateral views in conjunction with biplane tomography.

The origin of the tumour, in particular its relation to the thymus gland, must be studied. Tumours have been described as being thymic in origin when on closer examination they occupy the site of the thymus but have not arisen from it. Fibrosarcomata and lipomata have been mistakenly diagnosed in this way (Seybold, McDonald, Clagett, and Good, 1950 ; Schlumberger, 1951). A similar appearance presented in the present case.

The microscopic identification of these tumours is difficult. Schwannian tumours, both benign and malignant, must be excluded, and there is a similarity in their microscopic appearance. All three may be encapsulated, and infiltration is generally late in those that are malignant.

Antoni (1920) differentiated the histological pattern of neurilemmoma into types $A$ and $B$, 


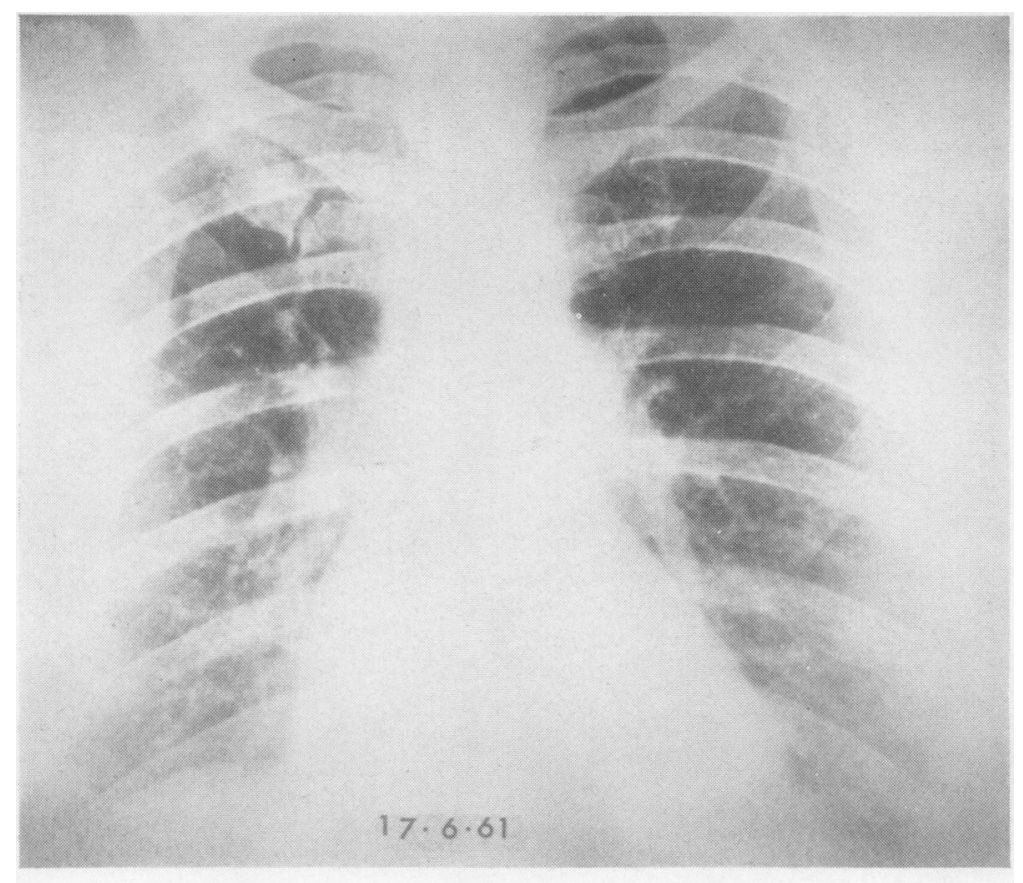

FIG. 2. (a) Postero-anterior and (b) right anterior oblique radiographs showing a mass projecting anteriorly at the level of the main-stem pulmonary artery.

both usually present in the same tumour and their junction being usually abrupt.

Antoni type A shows easily recognized spindleshaped Schwann cells arranged in bundles with the nuclei ovoid or rod-shaped and tending to regimentation in a palisade formation. The texture of the tumour is compact. Fine argyrophil fibres may be seen running parallel to the long axes of the cells. The nuclei have occasionally been seen arranged like bizarre Wagner-Meissner corpuscles.

Antoni type B shows a tissue of loose texture in which the Schwann cells may be arranged in a stellate pattern. Areas of degeneration are revealed as small microcysts. Vascular thickening due to perivascular hyalinization might give rise to spontaneous thromboses and areas of granulation tissue. Lipoid-laden foam cells, either intact or necrotic, might be seen ; xanthomatous changes have frequently been observed in mediastinal Schwannomas (Pachter and Lattes, 1963 ; Oberman and Abell, 1960; Russell and Rubinstein, 1963).

The malignant Schwannoma shows a cell pattern similar to the benign tumour ; sclerosis of vessels and areas of necrosis are usually apparent. Giant cell formation and polymorphism are more evident. The direction of the argyrophil fibres is inconstant. Cartilage and osteoid tissue have been seen (Russell and Rubinstein, 1963). 


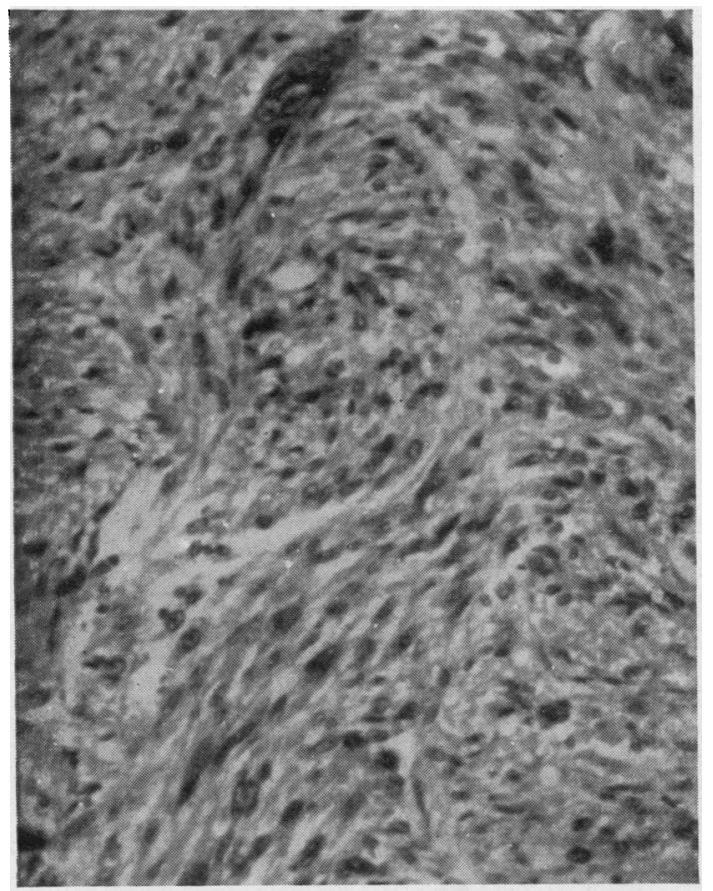

Fig. 3

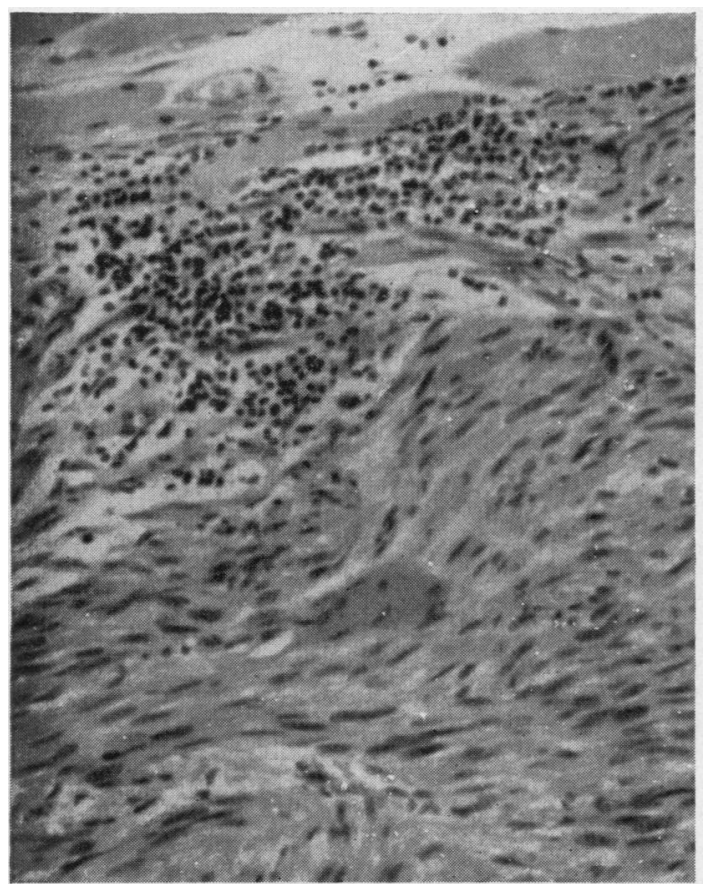

FIG. 5

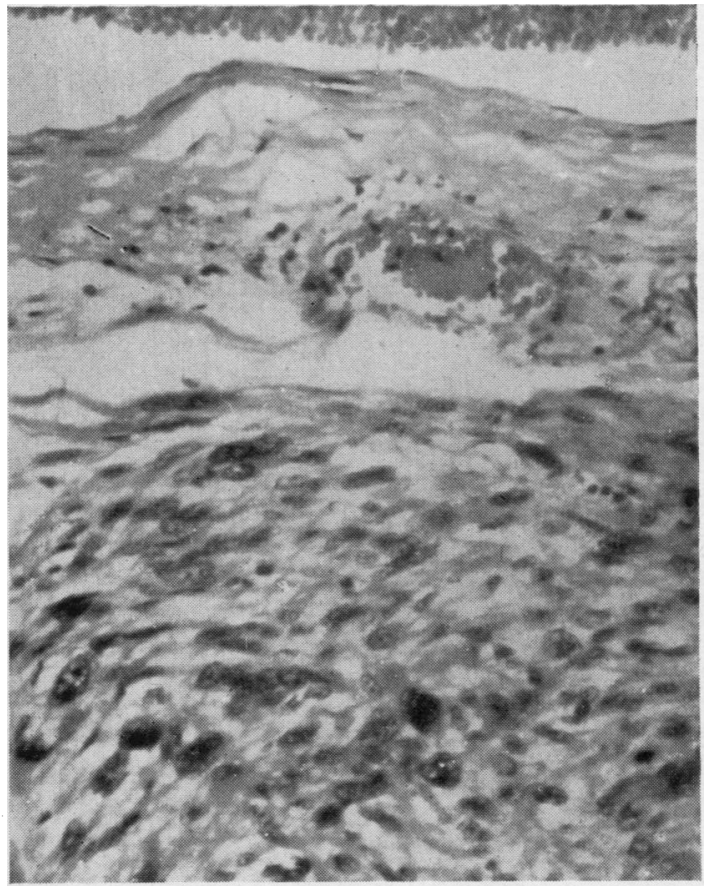

Fig. 4

FIG. 3. Smooth muscle cells showing some differentiation. The nuclei are elongated with blunt ends, and the tendency to palisade can be seen. $H$. and $E$.

FIG. 4. Section of tumour showing intact capsule. Note bizarre nuclei. $H$. and $E$.

FIG. 5. Photomicrograph of metastasis. Tumour cells infiltrating striated muscle fibres in upper part of figure. $H$. and $E$.

The cells in leiomyosarcoma may be arranged in interlacing bundles of spindle or strap-shaped cells. The nuclei may be in a palisade formation but are elongated with blunt ends. Pink-staining cytoplasm with intracytoplasmic myofibrils should be seen (Stout and Hill, 1958).

Anaplasia is present in every cell, and one or more than one mitosis in every high-powered field should be observed (Stout, 1953).

\section{SUMMARY}

A case of leiomyosarcoma of the anterior mediastinum is described. The tumour had been present for at least 18 months before its surgical 
excision. When the patient was last seen there were multiple metastases.

I thank Mr. M. Paneth, under whose care the patient was admitted and who performed the thoracotomy.

In addition, I wish to thank for their helpful criticism Dr. K. F. W. Hinson, Dr. G. Simon, and Dr. Duncan Craven; Dr. A. Kuper for the photomicrography, and Mr. P. J. Bishop, Librarian of the Institute of Diseases of the Chest.

I would also like to thank Miss Olive Higdon for secretarial services.

\section{REFERENCES}

Antoni, N. R. E. (1920). Über Rückenmarkstumoren und Neurofibrome: Studien zur pathologischen Anatomie und Embryogenese (mit einem klinischen Anhang). Bergmann, Munich.
Blades, B. (1946). Mediastinal tumors. Report of cases treated at Army Thoracic Surgery Centers in the United States. Ann. Surg., $123,749$.

Brewer, L. A. and Dolley, F. S. (1949). Tumors of the mediastinum. A discussion of diagnostic procedure and surgical treatment based on experience with 44 operated cases. Amer. Rev. Tuberc., 60, 419. Lyons, H. A., Calvy, G. L., and Sammons, B. P. (1959). The diagnosis and classification of mediastinal masses. I. A study of 782 cases. Ann. intern. Med., 51, 897.

Oberman, H. A., and Abell, M. R. (1960). Neurogenous neoplasms of the mediastinum. Cancer, 13,882

Pachter, M. R., and Lattes, R. (1963). Neurogenous tumors' of the mediastinum: A clinicopathologic study based on 50 cases. Dis. Chest, 44, 79 .

Russell, D. S., and Rubinstein, L. J. (1963). Pathology of Tumours of the Nervous System, 2nd ed. Arnold, London.

Schlumberger, H. G. (1951). Atlas of Tumor Pathology. Section V. Fascicle 18, Tumors of the Mediastinum, p. 12. Armed Forces Institute of Pathology, Washington, D.C.

Seybld W D McDonal J R., Claget, O. T and Good, C. A. (1950). Tumors of the thymus. J. thorac. Surg., 20, 195.

Stout, A. P. (1953). Atlas of Tumour Pathology, Section II, Fascicle 5, Tumors of Soft Tissue, p. 88. Armed Forces Institute of Pathology, Washington, D.C.

and Hill, W. T. (1958). Leiomyosarcoma of the superficial soft tissues. Cancer, 11, 844. 